\title{
Progress in the study of Asian Monsoon climate dynamics using dendrochronology
}

\author{
Brendan M. Buckley*, Rosanne D. D'Arrigo, Edward R. Cook, Gordon C. Jacoby, William E. Wright \\ Tree Ring Laboratory, Lamont-Doherty Earth Observatory, Columbia University, Palisades, USA; *bmb@|deo.columbia.edu
}

\section{Introduction}

Scientists at the Tree-Ring Laboratory of the Lamont-Doherty Earth Observatory of Columbia University in NewYork are entering the third year of a five-year project on Tree-Ring Reconstructions of Asian Monsoon Climate Dynamics (see www.ldeo. columbia.edu/res/fac/trl/). The scope of the project spans the entire Asian region linked to or affected by the monsoon, from Siberia, Mongolia and North Asia, to Australasia and Oceania, mainland Southeast Asia and the Indian subcontinent in the south. The first two years have heavily emphasized the building of tree-ring data networks for reconstructing features of Asian monsoon climate and the factors influencing its variability (e.g., Indo-Pacific sea surface temperature (SST) fields), in part for the purpose of driving General Circulation Model (GCM) estimates of monsoon climate variability with paleoclimate data spanning the past several centuries. A dearth of tree-ring data from the tropical regions prompted our commitment to obtaining such data from the Asian tropics first; hence our initial focus on field investigations in tropical Asia.

\section{Regional collaboration}

A project of this magnitude requires a strong commitment from regional collaborators, and the list of foreign participants that are integral to this project is far too exhaustive to present here. Importantly, we have helped to develop tree-ring laboratories at several institutions in Asia, and we have consistently worked to supply formal training in dendrochronological techniques. For example, the Laboratory of Tropical Dendrochronology at Kasetsart University in Bangkok, the Tree Ring Laboratory at Mongolian National University in Ulan Baatar, a facility at the Institut Teknologi Bandung in Java, Indonesia, and another at the

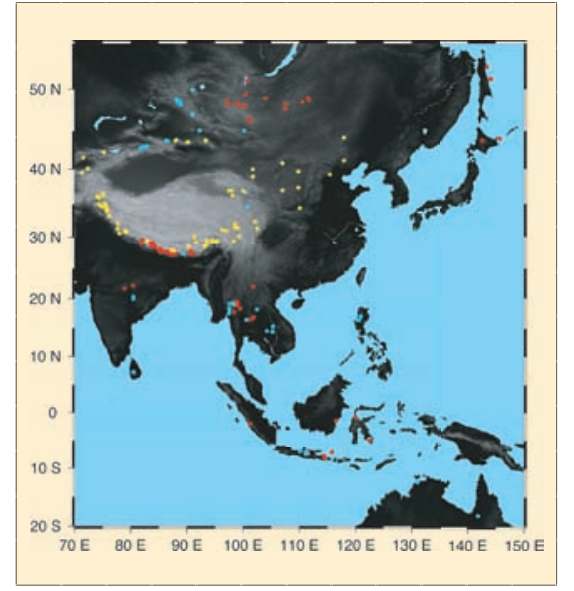

Figure 1: Map showing the Asian monsoon region that is the project focus. Red dots: tree-ring data locations that were available at the start. Yellow dots: data that have been contributed from various sources. Light blue dots: new data and chronologies that have been developed over the past ca. two years of field work in monsoon Asia.

Renewable Natural Resources Research Center in Jakar, Bhutan, are all fully functional. New programs are being developed at the University of Los Baños in the Philippines, and at the University of Peradeniya in Kandy, Sri Lanka. We have also developed close ties to regional tree-ring scientists from Lanzhou University in China, the Birbal Sahni Institute of Palaeobotany in Lucknow, India, and the Indian Institute of Tropical Meteorology in Pune. In all of these locations, we have defined our top priorities as true collaboration, education, capacity building and technology transfer, in order to insure that our research will have a lasting impact in Asia. In turn, our Asian collaborators have had much to teach us about the climate and environment of their respective regions, and have been instrumental in facilitating our ability to collect treering samples. This project has also benefited from contributors to the NOAA Paleoclimatology Data Bank (www.ncdc.noaa.gov/paleo/paleo. html) and from many individuals who have contributed data directly to our project.

\section{Developing a climate story}

Our efforts have already begun to yield results, as we have substantially increased our tree-ring data

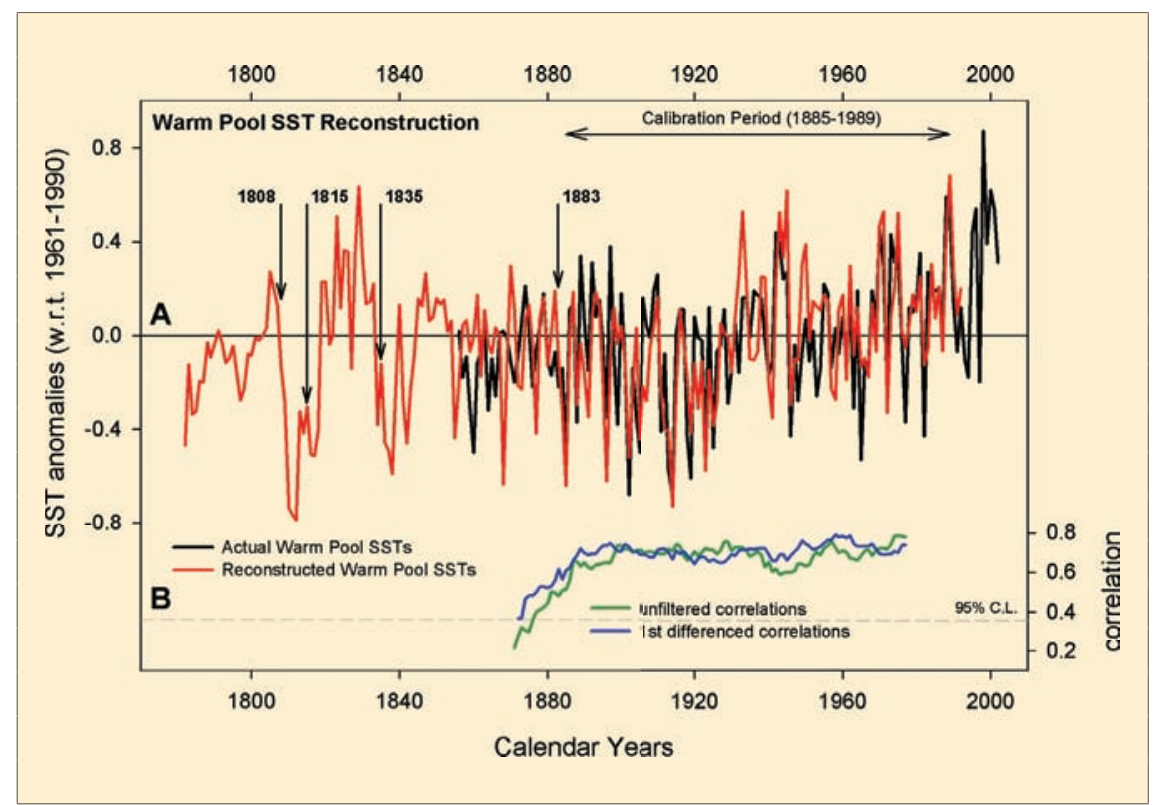

Figure 2: Indonesian warm pool SST reconstruction (D'Arrigo et al., in press). $\boldsymbol{A}$ shows actual (black) and reconstructed (red) September-November Indonesian warm pool SSTs. Several volcanic episodes during the 19th century are indicated with arrows. B shows running 31-year correlation plots between reconstruction and instrumental data. Correlations are calculated for both unfiltered data (green) and 1st differenced transforms (blue) (Fig. by Robert J. Wilson). 
network for the Asian monsoon region, particularly in the Asian tropics (see Fig. 1). It is critically important to the goals of our project that we define the role of the tropics in driving or modulating notable climate changes over the past 500 to 1000 years. We framed our project around analyzing three primary features of climate variability that were identified by Meehl and Arblaster (2002) as having links to variability in the strength of the monsoon; Indian Ocean SSTs, tropical Pacific SSTs, and land temperatures over the Tibetan Plateau and northern Eurasia. We are sampling tree-ring sites that are influenced by one or more of these monsoon-related features. For example, Buckley et al. (2005) demonstrated links between pine sites from Bhutan, India and Thailand, and all three of the abovementioned features, while D'Arrigo et al. (2005) modeled relationships between the North Pacific Index and the tropics, and D'Arrigo et al. (in press) developed a tree-ring and coral-based reconstruction of Indonesian warm pool SSTs (Fig. 2a). Many old teak logs buried in alluvial sediments may also yield extensions of our existing Indonesian chronologies by several centuries. Other efforts are resulting in new climate-sensitive records from sites across our study region, in places as diverse as Mongolia, the Philippines, and Laos.

Our studies are beginning to clarify periods of reduced monsoon strength that appear to be linked to SST variability in the eastern tropical Pacific. For example, a 450-year moisture-sensitive teak chronology that we have developed from northwestern Thailand (Fig. 3) shows marked reductions in inferred monsoon strength in the early to middle 1700 s. This finding is consistent with Dunbar et al. (1994), who showed persistent warm SST anomalies in the eastern tropical Pacific during this time, based on coral records from the Galapagos Islands. It is also consistent with the expected effects of persistent EI Niño conditions on rainfall in this area ofThailand, and agrees with a speleothem record from central India (Kevin

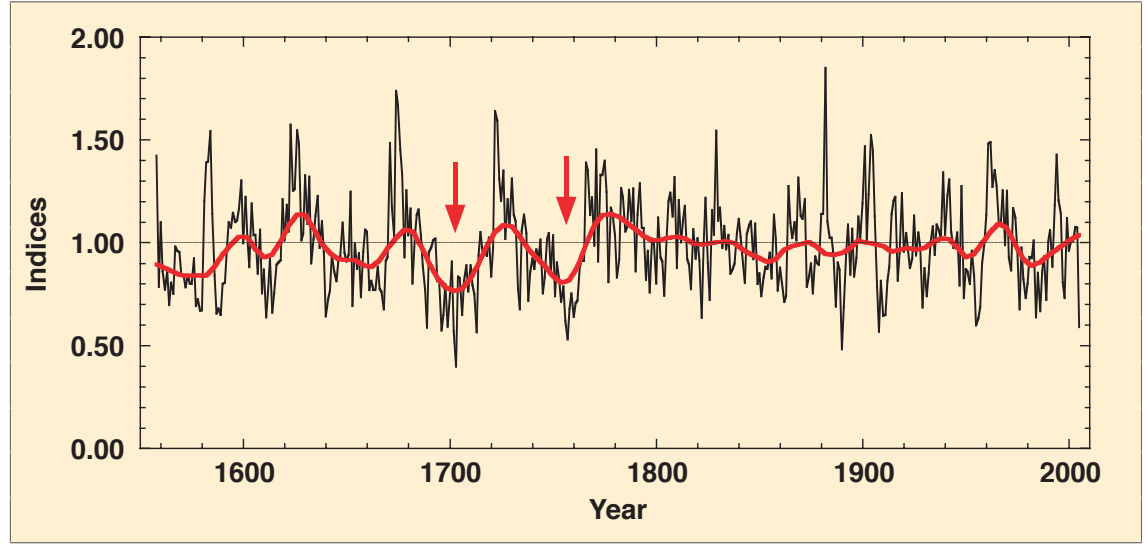

Figure 3: Plot of the MHS teak chronology from northwestern Thailand, developed from living trees and 57 stumps that remain from logging at the beginning of the 20th century. We made individual tree chronologies using 4-7 radii from each tree. The growth reductions in the early and mid-1700s mark periods of reduced monsoon strength that are likely related to warm SST anomalies in the eastern tropical Pacific, consistent with evidence from Dunbar et al (1994).

Cannariatto and Lowell Stott, pers. comm.) that indicates an unusually weak monsoon in central India at this time. The speleothem record also suggests enhanced monsoon activity throughout much of the Medieval Climate Anomaly (MCA) period that would be consistent with persistent La Niña-like cold SST anomalies in the eastern tropical Pacific. We have yet to build continuous tropical tree-ring chronologies that extend back far enough to analyze the MCA, although we have collected sub-fossil teak river logs and log coffin wood that date back to this period. We are collaborating with Drs. Cannariatto and Stott to compare isotopic records of these teak samples with their speleothem results, and see this as an important new avenue of research.

\section{Summary}

These and other recent studies demonstrate our ability to model past climate in the Asian monsoon region, and highlight the important role of tropical forcing on global climate. Combined with our very long tree-ring records from extratropical Asia, we anticipate millennial-length coverage at several key locations across the range of our developing Asian network. This research is ongoing but gives us hope for some very exciting results in the near future. Over the remaining three years of this grant, we anticipate that our efforts will result in an increased understanding of the mechanisms behind the Asian monsoon through regional reconstructions and modeling.

\section{Acknowledgements}

This five-year project is supported by the National Science Foundation's Paleoclimate Program (Grant OCE 04-02474), and runs until the end of July 2009.

\section{REFERENCES}

Buckley, B.M., Cook, B.I., Bhattacharyya, A., Dukpa, D., and Chaudhary, V., 2005: Global surface temperature signals in pine ring width chronologies from southern monsoon Asia. Geophysical Research Letters, 32: L20704, doi:10.1029/ 2005GLO23745, 2005.

D’Arrigo, R., Wilson, R., Deser, C., Wiles, G., Cook, E., Villalba, R., Tudhope, A., Cole, J., and Linsley, B., 2005: Tropical-North Pacific climate linkages over the past four centuries. Journal of Climate, 18: 5253-5265.

D’Arrigo, R., Wilson, R., Palmer, J., Krusic, P., Curtis, A., Sakulich, J., Bijaksana, S., Zulaikah, S., Ngkoimani, 0., and Tudhope, S. in press: Reconstructed Indonesian warm pool SSTs from tree rings and corals: linkages with ENSO and the Asian monsoon. Paleoceanography, 21:, doi:10.1029/ 2005PA001256, 2006

Dunbar, R.B., G.M. Wellington, M.W. Colgan and Glynn, P.W., 1994: Eastern Pacific sea surface temperature since 1600 A.D.: The $\delta^{18} 0$ record of climate variability in Galapagos corals. Paleoceanography 9(2): 291-315.

Meehl, G. and Arblaster, J., 2002: The tropospheric biennial oscillation and Asian-Australian monsoon rainfall. J. Climate, 15: 722-744. 